\title{
Erratum to Training of Upper Respiratory Endoscopy in the Horse Using Preserved Head and Neck
}

\author{
Fawzy A. Elnady ${ }^{1}$, Eldessouky Sheta ${ }^{2}$, Ashour K. Khalifa ${ }^{3}$ and Hamdy Rizk ${ }^{1}$ \\ ${ }^{1}$ Department of Anatomy and Embryology, Faculty of Veterinary Medicine, Cairo University, Giza, Egypt; ${ }^{2}$ Department of \\ Surgery, Anesthesiology and Radiology, Faculty of Veterinary Medicine, Cairo University, Giza, Egypt; ${ }^{3}$ Ministry of Interior, \\ Equine Department of Police General Security, Tripoli, Libya
}

In this manuscript which appeared in ALTEX (2015), 32(4), 384-387, http://dx.doi.org/10.14573/altex.1505111 the last paragraph on page 384 under the heading Specimen preparation should read:

Conventional plastination uses formalin for tissue fixation, acetone or alcohol for dehydration, various types of silicone polymer for impregnation (e.g. from BIODUR ${ }^{\circledR}$, Germany), and gas, light, or heat, depending on the polymer used, for curing. The Elnady Technique also involves fixation and dehydration, but employs a new non-silicone viscous polymer for impregnation, and follows a different curing process. In our preservation method, all processes run at room temperature.

http://dx.doi.org/10.14573/altex.1512121

\section{Corrigendum to Performance of the BGILUc ER TA Method in a qHTS Format}

\author{
Patricia Ceger ${ }^{1}$, David Allen ${ }^{1}$, Ruili Huang ${ }^{2}$, Menghang Xia ${ }^{2}$ and Warren Casey ${ }^{3}$ \\ ${ }^{1}$ Integrated Laboratory Systems, Inc., Research Triangle Park, North Carolina, USA; ${ }^{2}$ National Chemical Genomics Center, \\ National Center for Advancing Translational Sciences, National Institutes of Health, Rockville, Maryland, USA; \\ ${ }^{3}$ National Toxicology Program Interagency Center for the Evaluation of Alternative Toxicological Methods, National Institute \\ of Environmental Health Sciences, Research Triangle Park, North Carolina, USA
}

In this manuscript which appeared in ALTEX (2015), 32(4), 287-296, http://dx.doi.org/10.14573/altex.1505121 the legend of Figure 1 should read:

\section{Fig. 1: Linear regression analysis of $B G 1$ manual and $q H T S \mathrm{EC}_{\mathbf{5 0}} / \mathrm{AC}_{\mathbf{5 0}}$ values}

A linear regression analysis was conducted of $\mathrm{EC}_{50} / \mathrm{AC}_{50}$ values for 33 substances that tested positive in the $\mathrm{BG} 1$ manual and HTS methods. A list of the chemicals used to create Figure 1 is included in Table 2. The slope of the linear regression is 0.83 with $\mathrm{r}^{2}$ of 0.78 .

Further, the first sentences of Section 5.3 should be:

\subsection{Quantitative $\mathrm{EC}_{50} / \mathrm{AC}_{50}$ comparison}

We also evaluated the quantitative differences in $\mathrm{EC}_{50} / \mathrm{AC}_{50}$ values for the 33 positive substances in both the $\mathrm{BG} 1$ manual and qHTS methods (Fig. 1). The slope of the linear regression presented in Figure 1 is 0.83 with an $\mathrm{r}^{2}$ of 0.78 , indicating that, while qualitative classifications were identical for these substances, there were some quantitative differences on a per-chemical basis.

http://dx.doi.org/10.14573/altex.1512041 